\title{
openheart The benefits of marine omega-3s for preventing arrhythmias
}

James J DiNicolantonio, James OKeefe (B)

To cite: DiNicolantonio JJ, OKeefe $\mathrm{J}$. The benefits of marine omega-3s for preventing arrhythmias. Open Heart 2020;7:e000904. doi:10.1136/ openhrt-2018-000904

Received 17 July 2018 Revised 29 September 2018 Accepted 12 October 2018
Check for updates

(c) Author(s) (or their employer(s)) 2020. Re-use permitted under CC BY-NC. No commercial re-use. See rights and permissions. Published by BMJ.

Preventive Cardiology, Saint Luke's Mid America Heart Institute, Kansas City, Missouri, USA

Correspondence to Dr James J DiNicolantonio; jjdinicol@gmail.com

\section{MARINE OMEGA-3S FOR THE PREVENTION OF ARRHYTHMIAS}

Omega-3s have been theorised to increase membrane fluidity by reducing compression of the acyl chains of membrane phospholipid fatty acids, which can lead to a reduction in the 'spring-like' tension on membrane ion channels. This spring-like tension can reduce the ability of ions to freely move in and out of the ion channel and hence reduce its conductance. This is known as the "Andersen membrane spring-like tension hypothesis' and is just one way marine omega-3s may prevent arrhythmias. ${ }^{1}$ This theory states that the phospholipid cell membrane curves near the ion protein channel in order for the hydrophobic domains of the cell membrane to match up. The hydrophobic length of ion channel proteins is slightly less than the hydrophobic length of the acyl chains in the phospholipid bilayer, which causes a slight bend in the membrane, and this bend compresses the ion channel decreasing the space that ions can freely move in and out of the channel. However, supplementing with fish oil can prevent or reduce this compression increasing the movement of ions in and out of the channel. ${ }^{1}$ Other antiarrhythmic benefits of omega-3s include eicosapentaenoic acid (EPA)'s ability to be a competitive substrate for the enzymes that metabolise arachidonic acid (AA) to proinflammatory eicosanoids, which is partly how marine omega-3s reduce inflammation. ${ }^{2}$ EPA metabolites are also antiarrhythmic, whereas almost all metabolites from AA (and linoleic acid) are proarrhythmic. ${ }^{3}$

Dietary omega-3s are mainly consumed as triglycerides, which are absorbed as free fatty acids and monoglycerides. These fats then get rapidly resynthesised in the intestine and liver back to triglycerides with subsequent integration into chylomicrons, very low-density lipoprotein and low-density lipoprotein (LDL) (LDL can actually deliver omega-3s to tissues via LDL receptors). The omega-3 polyunsaturated fatty acids (PUFAs) can also be liberated from lipoproteins via lipoprotein and hepatic lipase and picked up by albumin via fatty acid-binding sites. The omega-3s are then carried by albumin to the heart, brain and other tissues for entrance into membrane phospholipids and stored as triglycerides. ${ }^{4}$ However, it is the liberated 'free-fatty acid' form of omega-3s that are thought to produce the antiarrhythmic properties. This free form of omega-3 can be mobilised from the plasma phospholipid during states of stress (severe exertion, sympathetic discharge) via phospholipases. ${ }^{56}$ If consumed on a regular basis, omega-3s will be adequately stored in the heart waiting to be released in order to protect against fatal arrhythmias. Their storage into cellular membranes of cardiac cells also likely provides antiarrhythmic benefits. One group of authors suggested that omega-3s, by accumulating into every heart cell, makes them resistant to arrhythmias. It was concluded that omega-3 benefits on arrhythmias are mainly due to '... the suppression of the L-type $\mathrm{Ca}^{2+}$ and voltage-dependent $\mathrm{Na}+$ currents...' By inhibiting the L-type $\mathrm{Ca}^{2+}$ channels, excess calcium coming into the cytosol is prevented, thereby reducing the risk of 'triggered arrhythmias', whereas inhibition of the voltage-dependent $\mathrm{Na}+$ currents prolongs the inactivated state of the $\mathrm{Na}+$ channel protecting the heart from ischaemiainduced arrhythmias (activation of the inactivated state can lead to an arrhythmia). ${ }^{4}$ The benefits of alpha-linolenic acid (ALA) are less certain, especially if ingested orally, as ALA is not stored to the extent long-chain omega-3s are. Docosahexaenoic acid (DHA) is the preferred storage form of omega-3s in both the heart and brain.

Despite fish oil inhibiting the $\mathrm{Na}$ ion channel, it does not lead to an upregulation of the number of $\mathrm{Na}$ channels per cardiomyocyte (unlike the class I antiarrhythmics some of which have been implicated in increased sudden death). The Na current 
can cause arrhythmias because it initiates action potentials in heart cells and if this occurs in partially depolarised myocytes, which require less depolarisation to exert an action potential, an arrhythmia can occur if this happens at a susceptible time in the electrical cycle of the heart. These susceptible times are reduced with the consumption of fish oil. Indeed, '...partially depolarised cells at the periphery of the ischaemic zone after an acute myocardial infarction (MI) are promptly and completely inactivated so that their potential arrhythmogenic role has been aborted by the presence of the omega- 3 fatty acids'. Thus, omega-3 PUFAs inhibit partially depolarised myocytes from exerting an action potential during a critical time after an MI that may lead to a fatal arrhythmia.

George Billman and Alexander Leaf were best known for their omega-3 experiments in animals. In one study, Billman and Leaf surgically induced large anterior wall MIs (via ligation of the left anterior coronary artery) in dogs. ${ }^{4}$ After 1 month, the animals were run on a treadmill and had their left circumflex artery occluded (using a hydraulic cuff) to induce ventricular fibrillation. However, when they were infused with EPA, five of the seven dogs were completely protected from fatal ventricular arrhythmias $(p<0.02)$. Similar results were found with DHA and ALA (six of eight dogs were protected, $\mathrm{p}<0.004$ for each). Billman and Leaf concluded, 'These results indicate that purified omega-3 fatty acids can prevent ischaemia-induced ventricular fibrillation in this dog model of sudden cardiac death'. In other studies from these authors, similar results were found. Indeed, infusing fish oil intravenously just prior to exercise-plusischaemia prevented ventricular fibrillation (in seven of eight dogs), which was not found with soybean oil (all five of five dogs developed ventricular fibrillation). ${ }^{7}$ The same results occurred in a subsequent study, whereby 10 of 13 dogs did not develop ventricular fibrillation when provided with omega-3 PUFAs. ${ }^{8}$ It is important to note that infusing omega-3 PUFAs allows them to be delivered right into the cardiac phospholipid membranes within seconds getting them to the site of action so they can quickly exert their antiarrhythmic effects. The benefits of omega-3s for preventing ischaemia-induced fatal ventricular fibrillation have been confirmed in other animal studies (including in rats and marmoset monkeys). ${ }^{8}$ The reduction of ischaemia-induced ventricular fibrillation is likely why marine omega-3s have been found to prevent sudden cardiac death in clinical trials in humans. ${ }^{9}{ }^{10} \mathrm{~A}$ randomised, double-blind, placebo-controlled clinical trial also found that giving $5.2 \mathrm{~g}$ of omega-3s to patients who had survived a MI for 12 weeks provided antiarrhythmic effects (a decrease in ventricular extrasystoles per 24 hours and an increase in heart rate variability). ${ }^{11}$

Among patients surviving a MI, sudden cardiac death makes up 50\%-60\% of all deaths from coronary artery disease. ${ }^{3}$ The European Society of Cardiology guidelines in 2003 recommended that fish oil be included in the management of patients who have experienced an acute MI. ${ }^{12}$ Data from randomised controlled trials as well as prospective studies indicate that fish or fish oil reduces cardiovascular mortality anywhere from $29 \%$ to $52 \%$ and sudden cardiac death from $45 \%$ to $81 \% .^{3}$ Indeed, fish oil has been found to significantly reduce mortality in just 3 months after an acute MI. ${ }^{10}$

Although death due to coronary heart disease has decreased in the USA since the 1960s, sudden cardiac deaths due to fatal arrhythmias remains high with ventricular fibrillation making up $80 \%$ of all sudden deaths in the USA. ${ }^{13}$ Cardiac arrhythmias can occur early during an ischaemic event or after reperfusion. Long-chain omega-3s have been found to reduce both ischaemic and reperfusion arrhythmias. Indeed, fish oil reduces ventricular fibrillation from coronary artery occlusion in numerous animal models (rats, monkeys, pigs and dogs) and has also been found to reduce myocardial ischaemiareperfusion injury (reduced ischaemic damage and fatal arrhythmias). ${ }^{14}$ Moreover, in the same experiment, almost twice as many animals were alive with fish oil supplementation $(76 \%)$ vs the omega- 6 corn oil group $(41 \%)$. This may be due to their ability to penetrate into endothelial cells, neutrophils, platelets, myocytes, and monocytes reducing inflammation, platelet aggregation, and the pro-arrhythmic effects of the 2-series eicosanoids from AA. ${ }^{13}$

Around 300000 people die every year in the USA from non-traumatic out-of-hospital sudden cardiac arrest with the majority of cases being caused by ventricular fibrillation due to thrombotic events. ${ }^{15} 16$ Marine omega-3s have evidence for reducing the risk of this complication. Studies suggest that if your intake of omega-3s is low, or intake of omega- 6 is high, then you are at a greater risk of having a heart attack as well as death due to a heart attack. Indeed, the reduction in sudden cardiac death in patients supplemented with marine omega-3s who had experienced a MI in GISSI-P became significant in just 4 months and this accounted for almost $60 \%$ of the mortality benefit. ${ }^{10}$ Approximately $50 \%-60 \%$ of all sudden deaths that occur within 1 hour of an acute MI are attributable to sustained ventricular arrhythmias, suggesting that omega-3s prevent fatal ventricular arrhythmias after an MI. In one randomised controlled trial in 115 acute MI patients, $1800 \mathrm{mg}$ of EPA given within 24 hours after a percutaneous coronary intervention (PCI) cut ventricular arrhythmias by almost $70 \%$ ( $7 \%$ vs $20.6 \%, \mathrm{p}=0.03) .{ }^{17}$

The incidence of sudden cardiac death in the general population of Western countries is almost 20-times greater than that in Japan. ${ }^{18}$ Interestingly, the EPA/DHA content in red cell membranes in Japan is estimated to sit at around 10\% compared with just $4.5 \%$ in Western countries. ${ }^{18}{ }^{19}$ Von Shacky concluded that in DART and GISSI-P the omega-3 index was estimated to have risen 'well above $8 \%$ ' in these studies. ${ }^{18}$ And the omega- 3 index in the control group in JELIS was estimated at $10 \% .{ }^{18} \mathrm{All}$ of this suggests that maintaining an omega-3 index of $8 \%$ but likely above $10 \%$ may provide the greatest benefit for reductions in cardiovascular risk. This may require intakes well above $3 \mathrm{~g} /$ day of EPA/DHA, as previous data 
have only found an increase in the omega-3 index from 3.08 to 5.84 with this amount of omega- 3 intake. ${ }^{20}{ }^{21}$ In 1997, the Food and Drug Administration ruled that the intake of $3 \mathrm{~g}$ of marine omega-3s per day was generally recognised as safe. ${ }^{22}$

Harris $e t$ al performed a meta-analysis of six epidemiological studies and found a $37 \%$ reduced risk of coronary heart disease death with an average EPA+DHA intake of $566 \mathrm{mg} /$ day. ${ }^{20}$ Moreover, an omega-3 index of $8 \%$ or higher is associated with a $90 \%$ reduction in the risk of sudden cardiac death compared with an index of $\leq 4 \% .{ }^{21}$ Stated differently, an omega-3 index of $\leq 4$ predicts a 10-fold greater risk of sudden cardiac death versus an omega-3 index of $\geq 8 .{ }^{23}$ Moreover, in another study, an omega-3 index of $5.0 \%$ vs $3.3 \%$ was associated with a $70 \%$ reduction in the risk of primary cardiac arrest. ${ }^{24}$ Another study found a $72 \%$ and $81 \%$ reduction in the risk of sudden cardiac death in those in the third and fourth quartiles of long-chain omega-3 PUFA compared with those in the lowest quartile. ${ }^{25}$

Patients suffering from a first-time non-fatal MI have also been found to have lower EPA and DHA content in adipose tissue suggesting lower dietary intake. ${ }^{26}$ Other data support the role of marine omega-3 fatty acids for reducing the risk of non-fatal as well as fatal MI. ${ }^{27}{ }^{28}$ The anti-inflammatory, antithrombotic, antiatherosclerotic as well as the triglyceride and blood pressure-lowering effects of marine omega-3s seem to occur at intakes around 3-4 $\mathrm{g}$ of EPA/DHA per day, whereas the antiarrhythmic benefits may occur at just $0.5-1 \mathrm{~g} /$ day. ${ }^{29}{ }^{30}$ The omega-3 index seems to support the notion that marine omega-3 intakes above $1 \mathrm{~g}$ of EPA/DHA per day may be needed to provide an optimal reduction in sudden cardiac death.

The Cardiovascular Health Study (CHS) found that in almost 4000 elderly adults without a history of cardiovascular disease those who consumed fish three times a week or more had a $58 \%$ lower risk of dying from an arrhythmic ischaemic heart disease (IHD) event and a $49 \%$ reduced risk of dying from IHD compared with those who only ate fish less than one time per week. ${ }^{31}$ In CHS, a 1 SD increase in EPA/DHA phospholipid content was associated with a 70\% decreased risk of fatal IHD and ALA was associated with a $48 \%$ decreased risk, whereas an increase in dietary linoleic acid (LA) was associated with a 2.42-fold increased risk. ${ }^{32}$ In CHS, two thirds of IHD deaths were due to arrhythmias.

In a double-blind placebo-controlled trial, compared with $5.2 \mathrm{~g}$ of corn oil, $5.2 \mathrm{~g}$ of omega-3 PUFAs (containing $4.3 \mathrm{~g} \mathrm{EPA}+\mathrm{DHA}$ ) lead to a greater reduction in the logarithmic number of ventricular extrasystoles/48 hours (5.2 to 4.6 vs 5.9 to 2.9 , respectively, although the difference was not statistically significant) ${ }^{33}$ This was measured by 48 -hour Holter monitoring at baseline and 16 weeks later and corresponded to a $42 \%$ reduction in the mean number of extrasystoles in the fish oil group. Moreover, 'The number of repetitive ventricular extrasystoles was decreased in the omega-3 group but increased in the corn oil group'. Additionally, the total number of ventricular extrasystoles per 48 hours went down from 360 to 18 in the omega-3 PUFA group, which was not as profound in the corn oil group (174 to 99). The authors noted, 'EPA and DHA are incorporated into the myocardial membrane after fish oil supplements often with a concomitant decrease in AA. These alterations may stabilise the myocardial membrane and make it more resistant to proarrhythmogenic stimuli...n-3 PUFAs protect against ventricular tachyarrhythmias in rats and monkeys and more so than PUFAs from the n- 6 family'. Thus, both human and animal studies show that marine omega-3 PUFAs are more potent antiarrhythmics versus omega- 6 PUFAs high in linoleic acid. This study is rather compelling as it confirms that omega- 6 may actually increase the number of repetitive ventricular extrasystoles. ${ }^{33}$

A reduction in the incidence of atrial and ventricular premature complexes, couplets and triplets in a doubleblind placebo-controlled trial in patients with cardiac arrhythmias was noted with $3 \mathrm{~g}$ /day of fish oil (providing $1 \mathrm{~g}$ of omega-3 fatty acids) compared with $3 \mathrm{~g}$ /day of olive oil. ${ }^{34}$ Compared with $4 \mathrm{~g}$ of olive oil, $4 \mathrm{~g}$ of fish oil (providing $2.6 \mathrm{~g}$ of EPA/DHA per day) caused a borderline significant increase in the time to first implantable cardioverter defibrillator event (ventricular tachycardia or ventricular fibrillation) or death due to any cause (28\% reduction, $\mathrm{p}=0.057),{ }^{35}$ which became significant $(31 \%$ reduction, $\mathrm{p}=0.033$ ) when therapies for probable ventricular tachycardia or fibrillation were included. Moreover, there was a $38 \%$ reduction in this endpoint $(p=0.034)$ for those who stayed on the protocol for at least 11 months and who had confirmed events. ${ }^{35}$

In a randomised, double-blind, placebo-controlled trial in patients with spontaneous ventricular premature complexes EPA/DHA (2.40 g of from cod liver oil) caused a significant $48 \%$ reduction in ventricular premature complexes after 16 weeks of supplementation, whereas $15 \mathrm{~mL}$ of sunflower seed oil (providing $5 \mathrm{~g}$ linoleic acid) led to a non-significant $25 \%$ reduction ( $\mathrm{p}$ for the difference $=0.052){ }^{36} 44 \%$ of patients in the cod liver group had a reduction in ventricular premature complexes of $>70 \%$ vs $15 \%$ in the sunflower seed oil $(p<0.01)$. The authors concluded, 'The results from this study indicate that dietary supplementation with a moderate dose of fish oil has antiarrhythmic effects, leading to a reduction in ventricular premature complexes in nearly half of the treated patients with frequent ventricular arrhythmias. Sunflower seed oil, which was chosen as placebo treatment, was much less effective, and the changes in ventricular premature complexes observed over the 16-week period in this group probably reflect spontaneous variability of ventricular arrhythmias and regression to the mean'. The authors also wrote, 'We chose sunflower seed oil as placebo, because corn oil, often used as placebo, had proarrhythmic effects in rats'. ${ }^{36}$

Omega-3 PUFA ( $1 \mathrm{~g}$ /day provided as fish oil) for 4 months has been found to significantly reduce atrial tachyarrhythmias by $59 \%$ and burden by $67 \% .{ }^{37}$ When fish oil was discontinued the number and burden of arrhythmias 
increased back to baseline levels. A prospective study following almost 5000 patients who were $\geq 65$ years found that the consumption of tuna or broiled/baked fish one to four times weekly was associated with a $28 \%$ lower risk of atrial fibrillation versus less than one time monthly (with a $31 \%$ reduction in those consuming fish five or more times weekly). ${ }^{38}$ The consumption of fried fish or fish sandwiches was not related to a reduced risk of atrial fibrillation.

In a randomised controlled trial, $2 \mathrm{~g}$ /day of omega-3 PUFA given at least 5 days prior to coronary artery bypass surgery reduced the risk of post-operative atrial fibrillation by more than $50 \%$ compared with control $(33.3 \%$ vs $15.2 \%, \mathrm{p}=0.013)$. Additionally, the patients given omega-3 PUFA were able to leave the hospital approximately 1 day earlier $(\mathrm{p}=0.017) .{ }^{39}$ In patients with a high number of premature ventricular complexes per day, 1.5 $\mathrm{g}$ of omega-3 PUFA reduces the number of complexes by 867 per 24 hours and significantly decreased heart rate by 2.1 beats per minute. ${ }^{40}$ However, in patients with sustained ventricular tachycardia, supplementing with omega-3 PUFA (1.8 g/day) may be proarrhythmic (at least compared with olive oil). Despite this, total mortality was lower in the fish oil group versus the olive oil placebo ( 4 vs $10, p=0.16){ }^{41}$

In the Study on Omega-3 Fatty Acids and Ventricular Arrhythmia (SOFA) supplementing with $2 \mathrm{~g}$ of fish oil (providing $799 \mathrm{~g}$ of EPA/DHA per day) vs $2 \mathrm{~g}$ of higholeic sunflower oil did not significantly reduce the primary endpoint (shock or antitachycardia pacing, for spontaneous ventricular tachyarrhythmias or death from any cause). ${ }^{42}$ However, in patients who had a prior MI, there was a tendency toward a longer event-free survival with fish oil versus the high-oleic sunflower oil 'placebo' $(\mathrm{p}=0.13)$. Moreover, death from any cause was numerically lower in the fish oil group (8 (3\%) vs $14(5 \%)$ ) as was MI $(1(0.4 \%)$ vs $3(1 \%))$. It is important to note that the results of any trial testing omega-3 PUFA will depend on the baseline patient population and concomitant medication use, the baseline intake of omega-3 and omega- 6 (and if either is high this will reduce any benefit from being found with omega-3 PUFA). Other important confounders include the type of fish consumed and the amount of supplemental omega-3 PUFA used in the study.

Lastly, a double-blind placebo-controlled trial in 55 post-MI patients found that $5.2 \mathrm{~g} /$ day of omega-3 PUFA for 12 weeks significantly increased heart rate variability (HRV) compared with baseline and to control. ${ }^{11} \mathrm{HRV}$ is a predictor of both arrhythmic events and mortality. ${ }^{3}$ And DHA levels in platelets are positively associated with increased HRV. ${ }^{43}$

Although epidemiological studies consistently show an inverse relationship between EPA and DHA and the incidence of sudden cardiac arrest, demonstrating such an effect in randomised intervention trials has been difficult. ${ }^{44}$ Yet, as outlined previously, studies clearly show that populations with high omega-3 intake have a low risk of sudden cardiac arrest. Thus, individuals with a low omega-3 index are prone to arrhythmias including cardiac arrest or atrial fibrillation, and these are the people who are most likely to derive the greatest benefit from an increased intake of EPA and DHA. ${ }^{44}$

\section{CONCLUSIONS}

The intake of marine omega-3s has consistently been found to have antiarrhythmic effects. When marine omega-3s are consumed, there is an increase in cellular membrane fluidity, inhibition of L-type calcium channels and a reduction in the chance of arrhythmic events during susceptible times. Prospective data suggest that maintaining an omega-3 index of about $8 \%$, which requires consuming seafood rich in omega-3 up to five times per week or consuming over $3 \mathrm{~g}$ of EPA and DHA per day, may provide the greatest protection against arrhythmic events.

Contributors Both authors contributed to the final paper.

Funding The authors have not declared a specific grant for this research from any funding agency in the public, commercial or not-for-profit sectors.

Competing interests JJD is the author of The Salt Fix, Superfuel and The Longevity Solution. J0 has an ownership interest in CardioTabs.

Patient consent for publication Not required.

Provenance and peer review Not commissioned; internally peer reviewed.

Open access This is an open access article distributed in accordance with the Creative Commons Attribution Non Commercial (CC BY-NC 4.0) license, which permits others to distribute, remix, adapt, build upon this work non-commercially, and license their derivative works on different terms, provided the original work is properly cited, appropriate credit is given, any changes made indicated, and the use is non-commercial. See: http://creativecommons.org/licenses/by-nc/4.0/.

ORCID iD

James OKeefe http://orcid.org/0000-0002-3376-5822

\section{REFERENCES}

1 Leaf A, Xiao YF, Kang JX, et al. Prevention of sudden cardiac death by $n-3$ polyunsaturated fatty acids. Pharmacol Ther 2003;98:355-77.

2 Mori TA, Beilin LJ. Omega-3 fatty acids and inflammation. Curr Atheroscler Rep 2004;6:461-7.

3 Reiffel JA, McDonald A. Antiarrhythmic effects of omega-3 fatty acids. Am J Cardiol 2006;98:50-60.

4 Billman GE, Kang JX, Leaf A. Prevention of sudden cardiac death by dietary pure omega-3 polyunsaturated fatty acids in dogs. Circulation 1999;99:2452-7.

5 Weylandt KH, Kang JX, Leaf A. Polyunsaturated fatty acids exert antiarrhythmic actions as free acids rather than in phospholipids. Lipids 1996;31:977-82.

6 Kang JX, Leaf A. Effects of long-chain polyunsaturated fatty acids on the contraction of neonatal rat cardiac myocytes. Proc Natl Acad Sci U S A 1994;91:9886-90.

7 Billman GE, Hallaq $H$, Leaf $A$. Prevention of ischemia-induced ventricular fibrillation by omega 3 fatty acids. Proc Natl Acad Sci U S A 1994;91:4427-30.

8 Billman GE, Kang JX, Leaf A. Prevention of ischemia-induced cardiac sudden death by $\mathrm{n}-3$ polyunsaturated fatty acids in dogs. Lipids 1997;32:1161-8.

9 Burr ML, Fehily AM, Gilbert JF, et al. Effects of changes in fat, fish, and fibre intakes on death and myocardial reinfarction: diet and reinfarction trial (dart). Lancet 1989;2:757-61.

10 Marchioli R, Barzi F, Bomba E, et al. Early protection against sudden death by $n-3$ polyunsaturated fatty acids after myocardial infarction: time-course analysis of the results of the Gruppo Italiano per lo Studio della Sopravvivenza nell'Infarto Miocardico (GISSI)Prevenzione. Circulation 2002;105:1897-903.

11 Christensen JH, Gustenhoff P, Korup E, et al. [n-3 polyunsaturated fatty acids, heart rate variability and ventricular arrhythmias in 
post-AMI-patients. A clinical controlled trial]. Ugeskr Laeger 1997;159:5525-9.

12 De Backer G, Ambrosioni E, Borch-Johnsen K, et al. European guidelines on cardiovascular disease prevention in clinical practice. third joint Task force of European and other societies on cardiovascular disease prevention in clinical practice. Eur Heart $J$ 2003;24:1601-10.

13 Nair SS, Leitch JW, Falconer J, et al. Prevention of cardiac arrhythmia by dietary ( $\mathrm{n}-3)$ polyunsaturated fatty acids and their mechanism of action. $J$ Nutr 1997;127:383-93.

14 Hock CE, Beck LD, Bodine RC, et al. Influence of dietary n-3 fatty acids on myocardial ischemia and reperfusion. Am J Physiol 1990;259:H1518-26.

15 AHA releases 2015 heart and stroke statistics. Available: http:// www.sca-aware.org/sca-news/aha-releases-2015-heart-and-strokestatistics

16 Sudden cardiac arrest: a healthcare crisis. Available: http://www.scaaware.org/about-sca

17 Doi M, Nosaka K, Miyoshi T, et al. Early eicosapentaenoic acid treatment after percutaneous coronary intervention reduces acute inflammatory responses and ventricular arrhythmias in patients with acute myocardial infarction: a randomized, controlled study. Int $J$ Cardiol 2014;176:577-82.

18 von Schacky C. Cardiovascular disease prevention and treatment. Prostaglandins Leukot Essent Fatty Acids 2009;81:193-8.

19 Itomura M, Fujioka S, Hamazaki K, et al. Factors influencing $\mathrm{EPA}+\mathrm{DHA}$ levels in red blood cells in Japan. In Vivo 2008;22:131-5.

20 Harris WS, Kris-Etherton PM, Harris KA. Intakes of long-chain omega-3 fatty acid associated with reduced risk for death from coronary heart disease in healthy adults. Curr Atheroscler Rep 2008;10:503-9.

21 Harris WS, von Schacky C. The omega-3 index: a new risk factor for death from coronary heart disease? Prev Med 2004;39:212-20.

22 Kris-Etherton PM, Harris WS, Appel LJ, et al. Fish consumption, fish oil, omega-3 fatty acids, and cardiovascular disease. Circulation 2002;106:2747-57.

23 von Schacky C, Harris WS. Cardiovascular benefits of omega-3 fatty acids. Cardiovasc Res 2007;73:310-5.

24 Siscovick DS, Raghunathan TE, King I, et al. Dietary intake and cell membrane levels of long-chain n-3 polyunsaturated fatty acids and the risk of primary cardiac arrest. JAMA 1995;274:1363-7.

25 Albert CM, Campos H, Stampfer MJ, et al. Blood levels of longchain $\mathrm{n}-3$ fatty acids and the risk of sudden death. N Engl $\mathrm{J}$ Med 2002;346:1113-8.

26 Pedersen JI, Ringstad J, Almendingen K, et al. Adipose tissue fatty acids and risk of myocardial infarction--a case-control study. Eur $J$ Clin Nutr 2000;54:618-25.

27 Hu FB, Bronner L, Willett WC, et al. Fish and omega-3 fatty acid intake and risk of coronary heart disease in women. JAMA 2002;287:1815-21.
28 Tavani A, Pelucchi C, Negri E, et al. N-3 polyunsaturated fatty acids, fish, and nonfatal acute myocardial infarction. Circulation 2001;104:2269-72.

29 DiNicolantonio JJ, Meier P, O'Keefe JH. Omega-3 polyunsaturated fatty acids for the prevention of cardiovascular disease: do formulation, dosage \& comparator matter? Mo Med 2013;110:495-8.

30 Westphal C, Konkel A, Schunck W-H. CYP-eicosanoids--a new link between omega- 3 fatty acids and cardiac disease? Prostaglandins Other Lipid Mediat 2011;96:99-108

31 Mozaffarian D, Lemaitre RN, Kuller LH, et al. Cardiac benefits of fish consumption may depend on the type of fish meal consumed: the cardiovascular health study. Circulation 2003;107:1372-7.

32 Lemaitre RN, King IB, Mozaffarian D, et al. N-3 polyunsaturated fatty acids, fatal ischemic heart disease, and nonfatal myocardial infarction in older adults: the cardiovascular health study. Am J Clin Nutr 2003;77:319-25.

33 Christensen JH, Gustenhoff P, Ejlersen E, et al. N-3 fatty acids and ventricular extrasystoles in patients with ventricular tachyarrhythmias. Nutr Res 1995;15:1-8.

34 Singer P, Wirth M. Can n-3 PUFA reduce cardiac arrhythmias? Results of a clinical trial. Prostaglandins Leukot Essent Fatty Acids 2004;71:153-9.

35 Leaf A, Albert CM, Josephson M, et al. Prevention of fatal arrhythmias in high-risk subjects by fish oil n-3 fatty acid intake. Circulation 2005;112:2762-8.

36 Sellmayer A, Witzgall H, Lorenz RL, et al. Effects of dietary fish oil on ventricular premature complexes. Am J Cardiol 1995;76:974-7.

37 Biscione F, Totteri A, De Vita A, et al. [Effect of omega-3 fatty acids on the prevention of atrial arrhythmias]. Ital Heart $J$ Suppl 2005;6:53-9.

38 Mozaffarian D, Psaty BM, Rimm EB, et al. Fish intake and risk of incident atrial fibrillation. Circulation 2004;110:368-73.

39 Calò L, Bianconi L, Colivicchi F, et al. N-3 fatty acids for the prevention of atrial fibrillation after coronary artery bypass surgery: a randomized, controlled trial. J Am Coll Cardiol 2005;45:1723-8.

40 Geelen A, Brouwer IA, Schouten EG, et al. Effects of n-3 fatty acids from fish on premature ventricular complexes and heart rate in humans. Am J Clin Nutr 2005;81:416-20.

41 Raitt MH, Connor WE, Morris C, et al. Fish oil supplementation and risk of ventricular tachycardia and ventricular fibrillation in patients with implantable defibrillators: a randomized controlled trial. JAMA 2005;293:2884-91.

42 Brouwer IA, Zock PL, Camm AJ, et al. Effect of fish oil on ventricular tachyarrhythmia and death in patients with implantable cardioverter defibrillators: the study on omega-3 fatty acids and ventricular arrhythmia (SOFA) randomized trial. JAMA 2006;295:2613-9.

43 Christensen JH, Korup E, Aarøe J, et al. Fish consumption, n-3 fatty acids in cell membranes, and heart rate variability in survivors of myocardial infarction with left ventricular dysfunction. Am J Cardiol 1997:79:1670-3.

44 von Schacky C. Omega-3 fatty acids: anti-arrhythmic, proarrhythmic, or both? Front Physiol 2012;3:88 